\title{
Relationship between productivity, quality and musculoskeletal disorder risk among deboning workers in a Chilean salmon industry
}

\author{
Ilardi, Juan S., ${ }^{\text {a, }}$ \\ ${ }^{a}$ Physical Therapist, MSc in Ergonomics, Ergonomics Consultant, Instituto de Seguridad del Trabajo, Diego \\ Portales Av. 2200, Puerto Montt, Región De Los Lagos, Chile.
}

\begin{abstract}
The purpose of this ergonomic investigation is to establish a relationship between quality, productivity and risk of musculoskeletal disorder (MSD) in manual bone-removal process in the salmon fish industry. The method consists in a follow up study of 14 workers in a lane that processes salmon steak. Time between each steak (work cycle), quality of the steak's meat through inspection of deepness and length of the gapping generated by the manual bone-removal process and risk for musculoskeletal disorders through OCRA method were considered for this study. IMC and musculoskeletal Nordic Questionnaire of Kourinka were applied to the workers evaluated. Fourteen women worker's completed the evaluation, age $37.67 \pm 8.1$, with $65.27 \pm 34.41$ months of experience, with an IMC of $27.18 \pm 3.87$ ( $1.52 \pm 0.057$ meters of height) at the time of the evaluation. Time for deboning per steak averaged $38 \pm 14$ seconds with $68.33 \pm 14.79$ steaks per hour per worker. In quality terms, $74 \%$ of the steaks were qualified as "premium steaks" and $26 \%$ as "grade or industrial" (lower category and cheapest price). OCRA index for the right hand average $13.79 \pm 4.59$ and $3.59 \pm 0.41$ for the left hand. From Nordic questionnaire $80 \%$ of the workers manifested musculoskeletal symptoms in the right hand/wrist, followed up by shoulder with $60 \%$ of the workers and arm/elbow with over $50 \%$. There was no statistically significant relationship between productivity and quality of the steak after manual bone removal process and between quality and MSD risk. However, there was a statistically significant relationship between productivity and MSD risk $(\mathrm{p}<0.05)$. Discussion around the results allows to see complementary results that did have strong correlation between MSD risk and the presence of lower grade salmon steaks and between areas that present musculoskeletal symptoms (MSS) and the intensity of the MSS $(\mathrm{p}<0.05)$. The results showed that further research is needed to validate these relationships, due to the increasing demands of health-care services from this productive sector, considering its importance for this region.
\end{abstract}

Keywords: productivity, quality, musculoskeletal, disorder, repetitive, aquaculture

\footnotetext{
* Corresponding author. E-mail: jsilardi@gmail.com
}

$1051-9815 / 12 / \$ 27.50$ @ 2012 - IOS Press and the authors. All rights reserved 


\section{Introduction}

Aquaculture industry in the region of Los Lagos is nowadays one of the most important economic activities, providing employment to thousands of people in the region. This industry has experience changes, including its great industrialization in the 1970 's, and of course, its greatest crisis due to the appearance of the infectious salmon anemia (ISA) by the year 2007-08 [17].

This latest crisis motivates companies to develop new strategies in both the industrial hygiene as the best use of the products 17].

The production of salmon, sliced or in fillets depends of various processes which include the use of important manual skills related to the use of tools such as knives and tweezers.

Quality and productivity are directly dependent on the skills of workers to process the pieces of salmon, where trimming and deboning become tasks that have a major role. Also, these tasks contain the highest risk for musculoskeletal disorders (MSD) due to the high frequency movements required by the upper limbs and a high amount of force that must be applied when using manual tools $[1,7,8]$.

It is also important to consider other conditions in which deboners work, such as static postures for long periods (postural work-load), cold environments (that involve manual dexterity, sensitivity and accuracy), wet floors (risk for slips and falls and for the transmission of low temperatures through the boots) and night shift work as potential risks for the appearance of work-related musculoskeletal disorder (WMSD) $[2,6,7,9,11,14]$.

The purpose of this ergonomic investigation was to establish a relationship between quality, productivity and risk of musculoskeletal disorder (MSD) in manual bone-removal process in the salmon fish industry.

\section{Method}

14 of 24 female right-handed workers were selected randomly to participate in the study, after giving there informed consent to participate. People who ended the study aged $37.67+/-8.1$ years, with an IMC of $27.18+/-3.87,1.52+/-0.05$ meters tall and with an experience deboning of $65.27+/-34.41$ months.

In a first stage, work was evaluated through the Occupational Repetitive Action (OCRA) method with a one hour follow-up register of actions, postures and perceived exertion (Borg scale). Soon after this register, workers answer a Nordic Musculoskeletal Questionnaire of Kuorinka.

Three previous follow-up studies were conducted for a fully comprehension of the characteristics of the task to focus this next analysis.

As the purpose of this investigation was to find if it is possible to link productivity, quality of the debone process and its risk for WMSD, the analysis of the variables studied was made through a correlation matrix created with the software "Statistica 7".

Finally, risk for WMSD evaluated through OCRA methodology and using data collected where analyzed through the software ErgoMET 2, developed by the MAPFRE Ergonomics Institute, S.A.

\section{Results}

\subsection{Production}

From the follow up study on the 14 workers whose principal activity was deboning, they manage to process successfully $530.66+/-219.22$ steaks per workday (as a team), and the time needed to debone a salmon steak was of $44+/-16$ seconds, this is equivalent to $68.33+/-14.79$ steaks per hour per worker (from a total of 1025 fillets observed).

\subsection{Quality}

The shredded of the fillets meat or the deeper the gap it gets, the lower the quality of those steaks of salmon, which means that the value of the fillets may vary. Soon after the deboner processes the pieces, these are inspected looking for a gap larger than 10 $\mathrm{cm}$, an indicator that helps the classification of the fillet.

The observations showed $70.24 \%$ of the fillets were qualified as "premium" and $29.76 \%$ as "grade or industrial" (lower category and cheapest price). This means that from the 1025 fillets observed, 305 suffer a gap due to the use of the tweezers on theme for the fishbone removal, shredding its meat.

\subsection{Risk for WMSD and discomfort}

OCRA index for $13.79+/-4.59$ for the right upper limb (RUL) and 3.59+/-0.41 for left upper limb (LUL). Results for RUL indicate "very high risk" for 
WMSD, achieving a red flag. Results for LUL indicate "low risk" for WMSD.

Musculoskeletal comfort measured through Nordic Musculoskeletal Questionnaire of Kuorinka showed that $80 \%$ of the workers manifested symptoms in the right hand/wrist, followed up by shoulder with $60 \%$ of the workers and arm/elbow with over $50 \%$.

Table 1

Correlations. Marked correlations are significant at $\mathrm{p}<, 05000 \mathrm{~N}=14$. (a) total fillets deboned per worker per hour, (b) fillets which suffer a gap greater than $10 \mathrm{cms}$. (c) fillets which suffer a gap shorter than $10 \mathrm{cms}$. (d) OCRA index result for left hand, (e) OCRA index result for right hand, (f) low gapped fillets divided by the total fillet deboned in percentage terms, (g) lifetime experience deboning in moths, (h) areas of the Kuorinka nordic questionnaire body map which present musculoskeletal discomfort, (i) intensity of discomfort from 0 to 5 in a visual analog scale, (j) Body mass index, and (k) age of the worker

\begin{tabular}{|c|c|c|c|c|c|c|c|c|c|c|c|}
\hline & $\begin{array}{l}\text { Deboned } \\
\text { fillets }\end{array}$ & $\begin{array}{r}\text { High } \\
\text { gapping }\end{array}$ & $\begin{array}{r}\text { Low } \\
\text { gapping }\end{array}$ & OCRA I & OCRA D & $\begin{array}{l}\text { Effici } \\
\text { ency }\end{array}$ & $\begin{array}{l}\text { Experie } \\
\text { nce }\end{array}$ & $\begin{array}{r}\text { Areas } \\
\text { with MSD }\end{array}$ & $\begin{array}{c}\text { Intensi } \\
\text { ty of MSD }\end{array}$ & BMI & Age \\
\hline $\begin{array}{l}\text { Deboned } \\
\text { fillets(a) }\end{array}$ & 1,00 & 0,39 & 0,85 & $-0,10$ & 0,55 & 0,06 & $-0,37$ & 0,11 & $-0,02$ & $-0,35$ & $-0,28$ \\
\hline $\begin{array}{c}\text { High } \\
\text { gapping(b) }\end{array}$ & 0,39 & 1,00 & $-0,15$ & 0,26 & 0,60 & $-0,87$ & $-0,00$ & $-0,01$ & 0,28 & $-0,01$ & 0,03 \\
\hline Low gapping(c) & 0,85 & $-0,15$ & 1,00 & $-0,25$ & 0,25 & 0,56 & $-0,39$ & 0,13 & $-0,18$ & $-0,37$ & $-0,32$ \\
\hline $\begin{array}{l}\text { OCRA left } \\
\text { hand(d) }\end{array}$ & $-0,10$ & 0,26 & $-0,25$ & 1,00 & 0,34 & $-0,24$ & $-0,09$ & 0,05 & 0,20 & 0,08 & 0,42 \\
\hline $\begin{array}{l}\text { OCRA right } \\
\text { hand(e) }\end{array}$ & 0,55 & 0,60 & 0,25 & 0,34 & 1,00 & $-0,27$ & 0,04 & 0,02 & 0,06 & $-0,05$ & $-0,19$ \\
\hline Efficiency(f) & 0,06 & $-0,87$ & 0,56 & $-0,24$ & $-0,27$ & 1,00 & $-0,09$ & 0,16 & $-0,19$ & $-0,16$ & $-0,20$ \\
\hline Experience(g) & $-0,37$ & $-0,00$ & $-0,39$ & $-0,09$ & 0,04 & $-0,09$ & 1,00 & 0,28 & 0,16 & 0,31 & 0,46 \\
\hline $\begin{array}{l}\text { Zones with } \\
\text { TME(h) }\end{array}$ & 0,11 & $-0,01$ & 0,13 & 0,05 & 0,02 & 0,16 & 0,28 & 1,00 & 0,73 & $-0,31$ & 0,39 \\
\hline $\begin{array}{l}\text { Intensity of } \\
\text { MSD(i) }\end{array}$ & $-0,02$ & 0,28 & $-0,18$ & 0,20 & 0,06 & $-0,19$ & 0,16 & 0,73 & 1,00 & $-0,20$ & 0,18 \\
\hline BMI(j) & $-0,35$ & $-0,01$ & $-0,37$ & 0,08 & $-0,05$ & $-0,16$ & 0,31 & $-0,31$ & $-0,20$ & 1,00 & 0,03 \\
\hline $\operatorname{Age}(\mathbf{k})$ & $-0,28$ & 0,03 & $-0,32$ & 0,42 & $-0,19$ & $-0,20$ & 0,46 & 0,39 & 0,18 & 0,03 & 1,00 \\
\hline
\end{tabular}

\section{Discussion}

It is known that repetitive tasks have a high risk for the occurrence of musculoskeletal disorders. In this line, it was possible to link individual production to this particular risk, but it was not possible to link efficiency with the risk of MSD and/or with individual production.

However, it was possible to see a trend in the correlations, shown on table 1 , of other factors influencing individual production such us experience in deboning, risk for WMSD and age.

It is interesting that production, in a way, it is quite reachable by deboners during a whole shift period, but with an enormous variability intra-worker and inter-worker, identifying individual productions from 55 to 85 , higher than the 50 to 70 fillets deboned established by the company.

It is clear that a bigger sample will be necessary to confirm the results, and of course, studies that include, in an integrated way, the study of other ergonomic factors.

During the field data collection and further analysis, it was possible to find a loss of a considerable amount of money because of the gapping and shredding of the fillet due to bad technique of deboning. This condition, if improved, could mean the recovery of US\$ 2.03 (top) per hour per worker, considering that in a daily shift there are almost two hundred workers and half of that number by the night shift.

From the experience gained during this research, it was possible to recognize a series of working conditions that are easily upgradeable with small steps which could allow a better quality of working life, but also performance or efficiency of the process of deboning. Considering, the amount of money saved through a better yield of the products and a lower rate of WMSD.

Some other factors should be included in future investigations such as the effect of the ambient in this 
work, psychosocial factors or contextual factors. While the salmon industry offers a lot of jobs, nowadays these jobs are considered seasonal, depending on the maturation of the salmons in their farms. At the time of the investigation, a high production season was on stage, having lots of active workers. The problem with these high-demand seasons, appears when production demand is so high that workers cannot maintain the pace of work, significantly increasing musculoskeletal injuries in the upper extremities, leaving people with a deterioration, not always successfully recovered before re-applying for jobs in these companies, causing a migration of people to companies in which they have no history of them and their injuries. Obviously, this situation will not last forever.

\section{Conclusion}

\subsection{Productivity}

Considering standards established by the company, an average of 50-70 fillets deboned per hour worked (this depending on the rigor mortis of the meat related to death time of the fish), follow up data showed that average individual production of deboned fillets was $68.33+/-14.79$ per worker, considering the product was a salar salmon (soft meat with enough death time for a low rigor mortis).

According to the results, the greater the individual production the greater the risk for the occurrence of musculoskeletal injuries for the right hand (table 1).

\subsection{Efficiency}

Efficiency was used as a quality indicator, considering fillets with a low gap over the total amount of fillets deboned per hour per worker. However there was no significant correlation significant correlation between efficiency and productivity or WMSD.

\subsection{Work-related Musculoskeletal Discomfort}

The application of the Nordic Musculoskeletal Questionnaire showed a strong correlation indicating that the more areas that present discomfort, the greater the intensity of discomfort.

\subsection{Quality and productivity}

The correlation between quality (amount of gapping on the fillet) and productivity (amount of deboned fillets per hour per worker), showed no significant relationship.

\section{References}

[1] P, Madeleine and T.M.T. Madsen, Changes in the amount and structure of motor variability during a deboning process are associated with work experience and neck-shoulder discomfort, Applied Ergonomics 40 (2009) 887-894.

[2] L. Punnet and D.H. Wegman, Work-related musculoskeletal disorders: the epidemiologic evidence and the debate, Journal of electromyography and Kinesiology 14 (2004) 13-23.

[3] Farrer, F. et al., 1994. "Manual de Ergonomía". Fundación MAPFRE, pág 364

[4] Erdinç, Oğuzhan and Yeow, Paul H. P.(2011) 'Proving external validity of ergonomics and quality relationship through review of real-world case studies', International Journal of Production Research, 49: 4, 949 - 962, First published on: 17 February 2010 (iFirst)

[5] Ashraf A. Shikdara,*, Biman Dasb (2003) "The relationship between worker satisfaction and productivity in a repetitive industrial task", Applied Ergonomics 34 (2003) 603-610.

[6] Chuansi Gaoa, Ã, Ingvar Holmera, John Abeysekerab (2008), "Slips and falls in a cold climate: Underfoot surface, footwear design and worker preferences for preventive measures ", Applied Ergonomics 39 (2008) 385-391.

[7] Reuben Escorpizo, Anne Moore (2007), "The effects of cycle time on the physical demands of a repetitive pickand-place task ", Applied Ergonomics 38 (2007) 609615

[8] B. Laursen á B.R. Jensen á G. Sjùgaard (1998), "Effect of speed and precision demands on human shoulder muscle electromyography during a repetitive task ", Eur J Appl Physiol (1998) 78: $544 \pm 548$.

[9] K.C. Parsons s (1995), "Ergonomics of the physical environment : International ergonomics standards concerning speech communication, danger signals, lighting, vibration and surface temperatures ", Applied Ergonomics Vol 26. No. 4, pp. 281-292, 1995.

[10] Hester J. Lipscomba, ${ }^{*}$, Dana Loomisb,c, Mary Anne McDonalda, Kristen Kucerab, Stephen Marshallb,d,e, Leiming Lia (2004), "Musculoskeletal symptoms among commercial fishers in North Carolina ", Applied Ergonomics 35 (2004) 417-426

[11] Ronald Hew, Hein A.M. Daanen and George Havenith (1995), "Physiological criteria for functioning of hands in the cold : A review ", Applied Ergonomics Vol. 26, No. 1, pp. 5-13, 1995.

[12] Ashraf A. Shikdara,*, Biman Dasb (2003), "The relationship between worker satisfaction and productivity in a repetitive industrial task ", Applied Ergonomics 34 (2003) 603-610.

[13] Pascal Madeleinea,*, Birthe Lundagerb, Michael Voigta, Lars Arendt-Nielsena (2003), "Standardized 
low-load repetitive work: evidence of different motor control strategies between experienced workers and a reference group ", Applied Ergonomics 34 (2003) 533542 .

[14] Inger Arvidssona, $b, *$, Ingrid Akessona, Gert-Ake Hanssona (2003), "Wrist movements among females in a repetitive, non-forceful work ", Applied Ergonomics 34 (2003) 309-316 .

[15] M. Borda, Annual Report 2010, http://www.multiexportfood.com/site/Memoria_Anual/ 2010/Memoria_FINAL_2011_Agosto.pdf 